\title{
User Awareness about Information Systems Usability
}

\author{
Ana-Maria SUDUC ${ }^{1}$, Mihai BÎZOI ${ }^{1}$, Florin Gheorghe FILIP ${ }^{2}$ \\ ${ }^{1}$ VALAHIA University of Targoviste, \\ Blvd. Carol I, No. 2, 130024, Targoviste, Dambovita, ROMANIA \\ ${ }^{2}$ Romanian Academy, Bucharest, ROMANIA
}

\begin{abstract}
The user-interface represents one very important aspect in the use of the information systems. The usability and acceptability of an information system, to a great extend, depend on the user-interface quality. The computer technology advances have changed the role of the end-user. The end-user development has become the most commonly used form of programming. It includes customization, integration and extension activities which may lead to a significant alteration of the system and may raise serious issues concerning correctness and consistency, security, and privacy. This paper presents and discusses the results of a survey meant to identify the users' awareness on the information systems usability, when users are viewed as developers.
\end{abstract}

Keywords: human-machine interface, usability criteria, end-user development, risks

\section{Introduction}

The HCI research field has experienced a rapid growth over the years, from the simple command line interfaces to the latest technological proposals which include tangible, embedded, embodied, ubiquitous, pervasive, context-aware, perceptual, mobile, and handheld user interfaces [1] [2]. Users expect from developers to create advanced interactive interfaces which are easy to use and easy to learn [3]. Unfortunately these interfaces are difficult to design and implement. As user interfaces became easier to use, they became harder to create [4].

Many technological innovations rely on the user-interface to transform the technological complexity into a usable product. Only the technology itself may not gain the user acceptance. The user experience or how the user perceives the final product experience is the acceptance key. attributes such as performance, security or maintainability, which contribute to the quality of software [5]. A bad user-interface can generate a series of negative consequences which widely range from increased completion of the task time, decreased productivity, lack of job satisfaction, inaccessibility for people with disabilities, to negative impact on people, data and environment. Actually, all these aspects represent risks in information systems (IS) usage. A special attention given to the user-interface design, in order to obtain "universal usability" [6], can significantly decrease these risks.

\section{End-user as Information System Designer}

In 2009, Fisher et al. [7] noticed that "software development is no longer the exclusive activity of professional software engineers" (Figure 1).

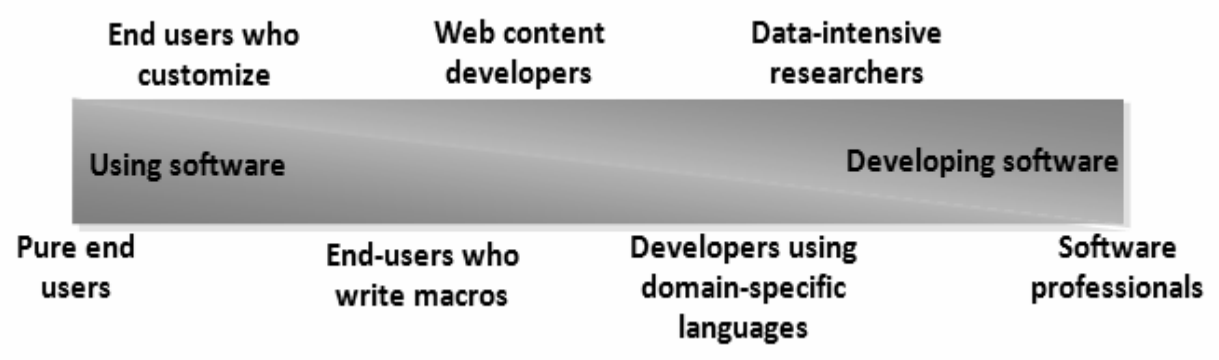

Figure 1. The spectrum of software related activities[7]

The most challenging task in the user-interface design is not just to provide the required functionality, but also to "design for" specific
Many researchers and developers have focused, in the last years, on how to make information systems not only easy to use but 
also easy to develop, meaning end users should be able to adapt their systems [8]. Different methods have been proposed to ease the transition between using an application and tailoring it at different levels of complexity [9].

A wide range of information systems are tailorable to the end-user, starting from the general purpose software (e.g. desktop operating systems, word processing software, spreadsheet software etc.) to domain specific software. These environments allow for user expressiveness in computing approach, function preferences, aesthetic layout and much more. Tailorable technologies support user goals, intentions, metaphor, and use patterns in the selection and integration of technology functions in the creation of unique information systems [10]. There have been identified several benefits of end-user development such as improved decision making, improved productivity and increased satisfaction of end users, but also risks: mismatches between tools and applications, lack of testing, inability to identify correct and complete information requirements and failure to back up data [11].

There are different levels of tailoring: customization (modifications of the existing components), integration (creation of new subassemblies of components) and extension (creation of new components by writing program code) [12]. The information systems which provide the last two levels of tailoring, namely integration and extension, enable end-users to substantially alter systems, which "creates a number of obvious issues concerning correctness and consistency, security and privacy" [8].

Software environments for end-user development address people with different training, culture, skills and technical abilities, etc. The question which arises is: "Are the end-user development products (the tailored information system) really usable?" Thereby an evaluation of the perception on usability criteria of the information systems users, as secondary developers, is pertinent.

\section{Usability}

According to ISO 9241-11 (1988) and ISO 9241-171 (2008), for a product to be usable and accessible users should be able to use it to achieve their goals in an acceptable amount of time, and be satisfied with the results [13].

The new draft standard ISO/IEC CD 25010.2 (2008) proposes a more comprehensive breakdown of quality in use into usability in use, flexibility in use, and safety.

Usability in use corresponds to the ISO 924111 definition of usability as effectiveness, efficiency, and satisfaction. The effectiveness is provided if the user can successfully and correctly fulfil his objectives. The assistance quality within the interface can have a great impact on the effectiveness. The interface should be as informative as possible [14]. Efficiency can be described as the speed (with accuracy) in which users can complete the tasks for which they use the product [15]. Satisfaction is composed of comfort (overall physiological or emotional responses to use of the system) and acceptability of use (overall attitude towards the system, or the user's perception of specific aspects) [16].

Flexibility in use is a measure of the extent to which the product is usable in all potential contexts of use, including accessibility. Safety is concerned with minimising undesirable consequences [13].

The most known reasons to measure usability in a product design process are: (a) a deeper understanding of the user needs and (b) product improvement in order to provide a better user experience.

\section{Method and Results}

In 2009, Bevan published a list of risks associated with usability. The main identified risks categories are the following: (a) increased development costs to produce an acceptable system, (b) poor products sales, (c) poor productivity and (d) increased support and maintenance costs.

Starting from the broader definition of usability given by ISO/IEC CD 25010.2 (2008) and from the Bevan's list [17] of benefits and risks associated with usability, a 
questionnaire for evaluating the user awareness on different usability aspects was conceived.

Even it includes several questions regarding users' satisfaction, the questionnaire is far from Questionnaire for User Interaction Satisfaction developed by Shneiderman and refined by Chin, Diehl and Norm [18] (http://www.lap.umd.edu/quis/). The survey is nor a usability test. The objective of the study was limited to investigating the users' perception on the usability of the information systems which they frequently use and on the interfaces of these systems and to the software, in general, by using the terminology and the definition given by ISO/IEC CD 25010.2. The users' perception on the user interface importance and its major deficiencies and the negative consequences experienced by the respondents were investigated too.

The authors' assumption for undertakening this study was that if the end-users understand the usability aspects and the importance of these aspects, they probably are able to tailor the information system as the unique system they obtained to be usable. Normally, it is the tailorable software developer's duty to provide a system which is usable in all potential contexts of use. But, sometimes, the user' expectations and actions exceed the developer's predictions.

The study was carried out at the end of 2009 (from 15 of November until 5 of December) and was based on a questionnaire, posted on a website. The questionnaire included questions with single and multiple answers.

Invitations to fill out the questionnaire were distributed via email to a specific target group.

The target group included students of the Electrical Engineering Faculty (License: Automatic Control and Applied Informatics, Electronics and Telecommunications; Master: Advanced Automatic Control, Product Development and Industrial Informatics), Valahia University of Targoviste, and university and secondary school teachers. Besides the participants from the target group there were also other persons. The students were encouraged to forward the link to the questionnaire also to other interested colleagues and friends.

\subsection{Respondents' profile}

159 persons participated to the study. The respondents group included $72 \%$ students, $11 \%$ teachers and $17 \%$ persons from other categories. A percentage of $71 \%$ were 18 to 26 years old, $15 \%-26$ to $35,8 \%-35$ to 50 and $6 \%$ were over 60 years old. The majority of $80 \%$ of respondents work or study in a technical area. A percentage of $13 \%$ of respondents work or study in the sociohumanistic disciplines and 7\% in other areas of activity.

A percentage of $54.09 \%$ of the respondents frequently use domain - specific software (modelling, simulation, design software, etc.) which more likely provide tailoring features. $82.39 \%$ of respondents often use general purpose information systems like office software or e-mail. $64.41 \%$ of respondents frequently use entertainment software (e.g. games).

In order to have a clearer vision over the software that the participants to the study are referring to, in the next questions regarding to usability, the respondents had to estimate the percentage of the online applications in the total number of the software they are frequently use. $7.55 \%$ are using frequently in percentage of $75 \%-100 \%$ online applications, $29.56 \%$ in percentage of $50 \%-75 \%, 33.96 \%$ in $25 \%-50 \%$ and $28.93 \%$ are using frequently online application in percentage of $0-25 \%$.

\subsection{End-user perception}

The first question about usability was related to the software they frequently use. The aim of this question was to determine, to a certain degree, what are the respondents' perceptions, expectations and dissatisfactions on these systems, in particular, and on software in general.

The participants were asked to give grades from 1 (Disagree) to 5 (Agree) to several usability criteria regarding the software they often use: (a) easy to use, (b) visually attractive, (c) intuitive, (d) with a terminology easy to understand, (e) with information well structured, (f) with low response times, (g) in accord with my expectations and (h) provide clear error messages which lead to a quick problem solving. 


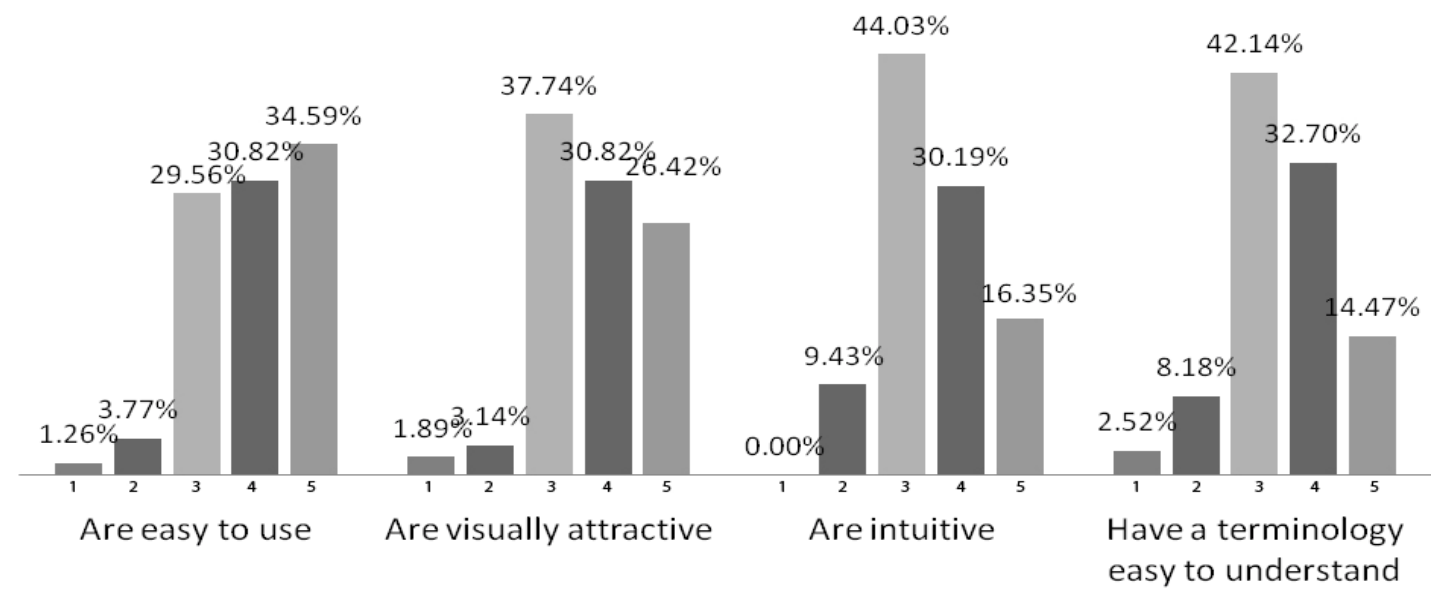

Figure 2. The usability evaluation of the software which the respondents frequently use (I).

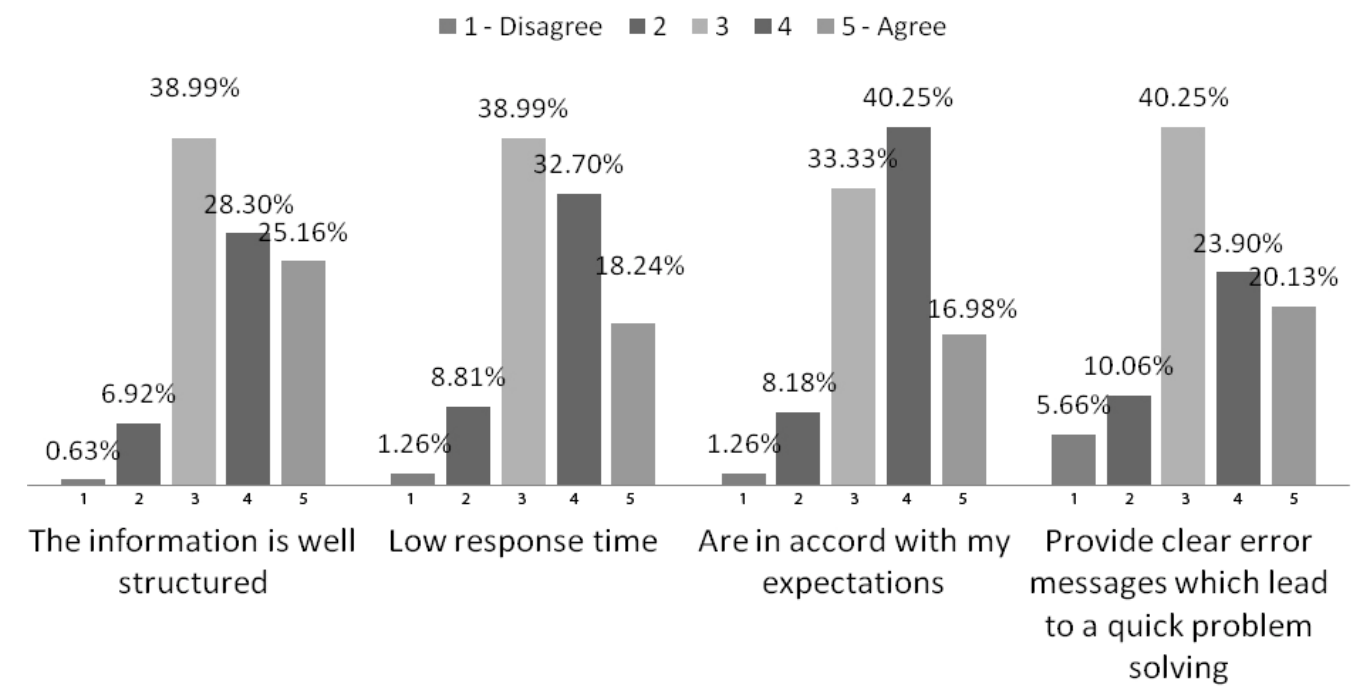

Figure 3. The usability evaluation of the software which the respondents frequently use (II).

It can be observed (Figure 2 and Figure 3) that most of the participants consider that the software which they frequently use is easy to use $(34.59 \%$ gave grade $5,30.82 \%$ gave grade 4 and $29.56 \%$ gave grade 3 ).

Except the criteria regarding the accordance of the software with the user expectations, which received grade 4 from the most of the respondents, to all the other criteria, the peaks are on grade 3 . It must be noted that to all criteria the balance turn to a positive evaluation.

When asked to assess the user-interface importance for an adequate information systems usage, the respondents considered as important in percentage of $95 \%$ (very important- $26 \%$, important- $42 \%$, quite important - $27 \%$ ).
To an identical question in a study made in 2008 on users' perception on information systems misuse risks [19], the 2008 survey' participants evaluated the user interface as important only in the percentage of $73 \%$ (Table 1).

Table 1. User-interface importance

\begin{tabular}{|c|c|c|c|}
\hline & & 2008 & 2009 \\
\hline \multirow{5}{*}{$\begin{array}{c}\text { How } \\
\text { important } \\
\text { is the user- } \\
\text { interface } \\
\text { for the } \\
\text { information } \\
\text { system } \\
\text { success? }\end{array}$} & Not important & $1.59 \%$ & $0.00 \%$ \\
\hline & $\begin{array}{l}\text { Somewhat } \\
\text { important }\end{array}$ & $11.11 \%$ & $5.03 \%$ \\
\hline & Quite important & $29.37 \%$ & $27.04 \%$ \\
\hline & Important & $33.33 \%$ & $42.14 \%$ \\
\hline & Very important & $24.60 \%$ & $25.79 \%$ \\
\hline
\end{tabular}


Unlike the participants to the 2008 survey, the 2009 respondents consider in a much larger proportion that the interface is important for an adequate use of the information system. It is important to notice that each participant gave a smaller or bigger importance to the interface (nobody ticked the "Not important" answer).

The respondents had also to estimate to what extent the user interface contributes to the software success. A percentage of $59 \%$ considered that the interface contributes in more than $50 \%$ to the system success.

These results show that users are usually aware that the user-interface contributes, to a great extent, to the information system success and to a better user experience.
Starting from the ISO/IEC CD 25010.2 (2008) definition of usability, there were formulated three questions which aimed at evaluating the users' perception on different information systems usability aspects and terminology.

The survey participants had to indicate what usability aspects they consider as most important features that a user-interface should provide (Figure 4 and Figure 5). There were listed 7 usability aspects. There were no restrictions for the number of aspects which they could indicate as the most important. Thus the participants could thick as many usability aspects as they wanted to (even all). Each aspect received "the most important" grade by a part of the respondents.

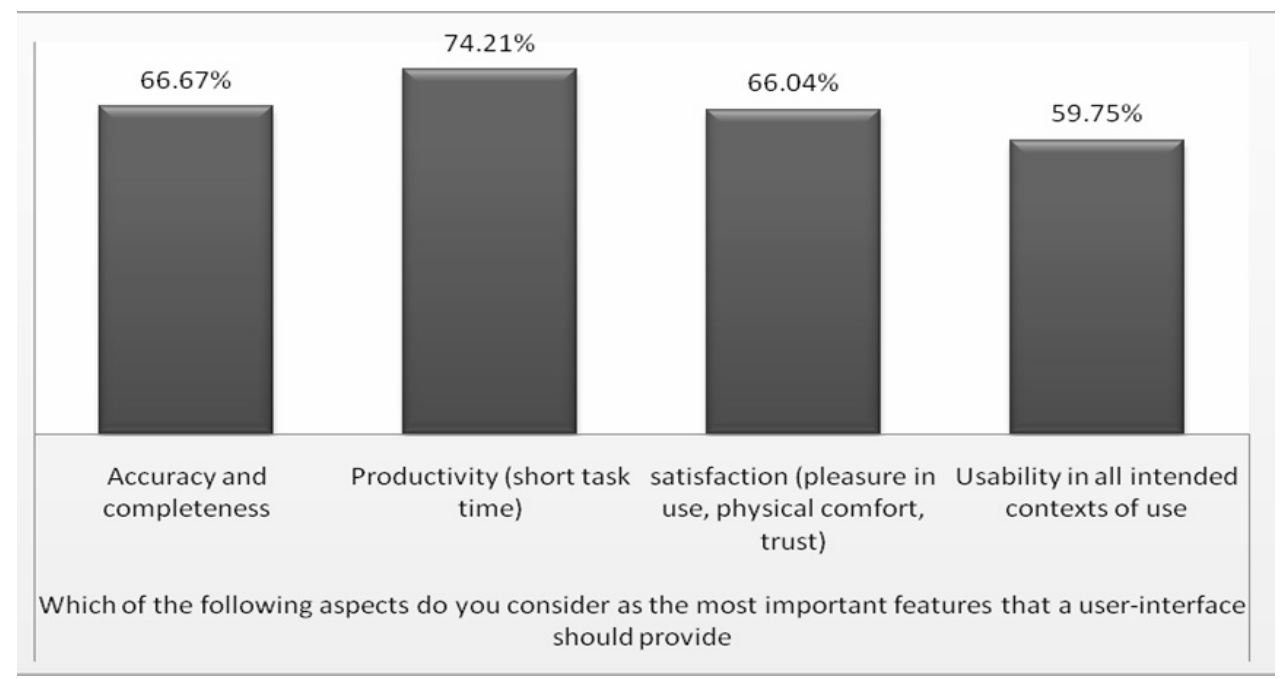

Figure 4. Features which an information system user-interface should provide (I)

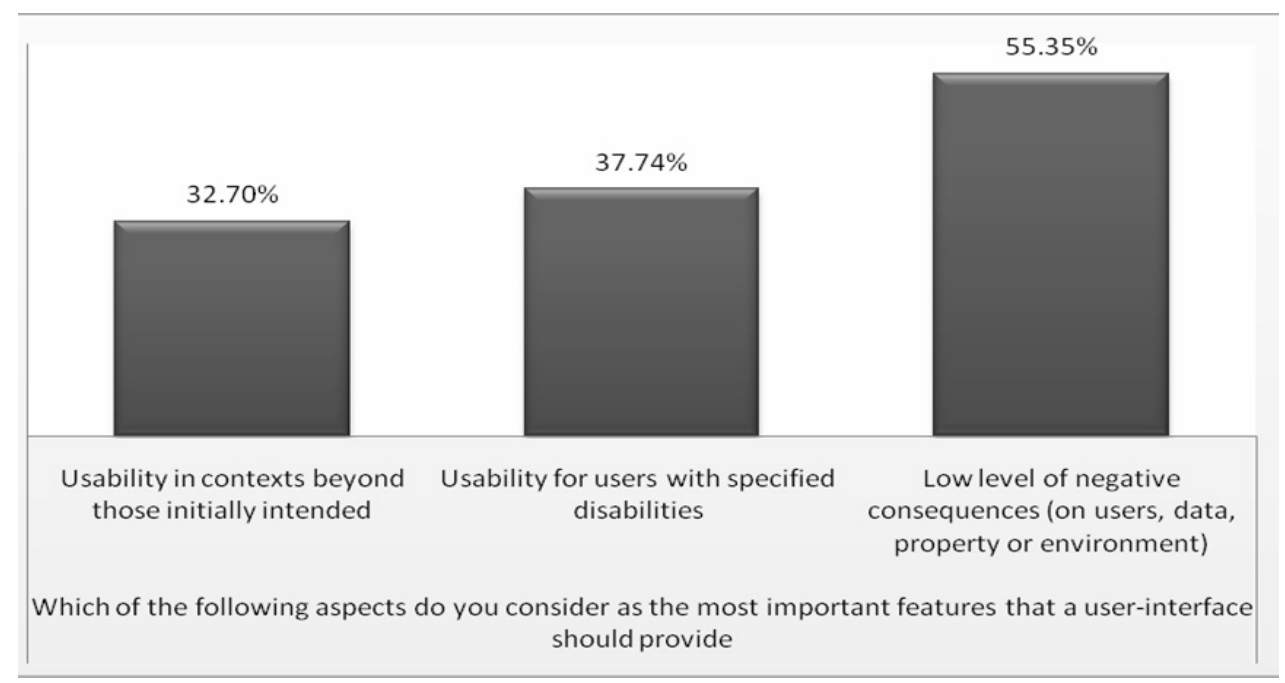

Figure 5. Features which an information system user-interface should provide (II) 
Except usability in contexts beyond those initially indented and usability for users with specified disabilities, all the other usability aspects were appreciated as the most important features that a user-interface should provide by more than $50 \%$ of the respondents.

It can be noticed that the users attached a great importance to the first three criteria, which actually represents the definition of the usability according to the ISO 92411 (1994) standard. The greatest importance was given to productivity (short task time).

Regarding the most serious deficiencies of an user-interface, the user had to indicate from a list of 12 deficiencies: (a) a too complex interface, (b) incomplete error messages, (c) improper organization of the information, (d) unpredictable interface, (e) deceptive interface, (f) non attractive interface, (g) interface which do not follow the standards, (h) non user-friendly interface, (i) interface which do not include special features for users with disabilities, (j) delayed feedback, (k) low personal data protection, and (l) others. The low personal data protection was the most serious deficiency pointed-out by $71.07 \%$ of the respondents. On the userinterface deficiencies top, the second place was occupied by incomplete error messages, voted by $62.26 \%$ of the respondents. Delayed feedback $(53.46 \%)$, improper organization of the information (58.49\%) and deceptive interface $(52.20 \%)$ deficiencies were also voted by more than $50 \%$ of the respondents.
At the end, the participants to the study were asked to indicate the negative consequences which they have ever experienced due to an inadequate user-interface. In a decreasing order of reported incidents, the negative consequences were: wasted time $(77.36 \%$ of the respondents experienced this consequence), frustration/stress (61.64\%), lost data (42.14\%), low productivity $(32.08 \%)$, others $(26.42 \%)$ and financial losses $(7.55 \%)$ (Figure 6).

It can be noticed that only a small part of the survey participants experienced financial losses due to an inadequate user-interface.

It can be noticed that many respondents were not satisfied with the response time of the information systems they used and most of the study participants indicated productivity as the main aspect that an interface should provide. The most frequent negative consequence that the user experienced due to an inadequate user-interface is wasted time (77.36\% of the respondents).

These observations indicate system response time as an aspect which the users perceive as very important. The delays can stop the user activity and can generate dissatisfaction, stress and even decreased performance. The delays in human-computer interaction can influence the productivity, work satisfaction, health and user safety.

The recent studies showed that any delay, no matter how small is, has negative

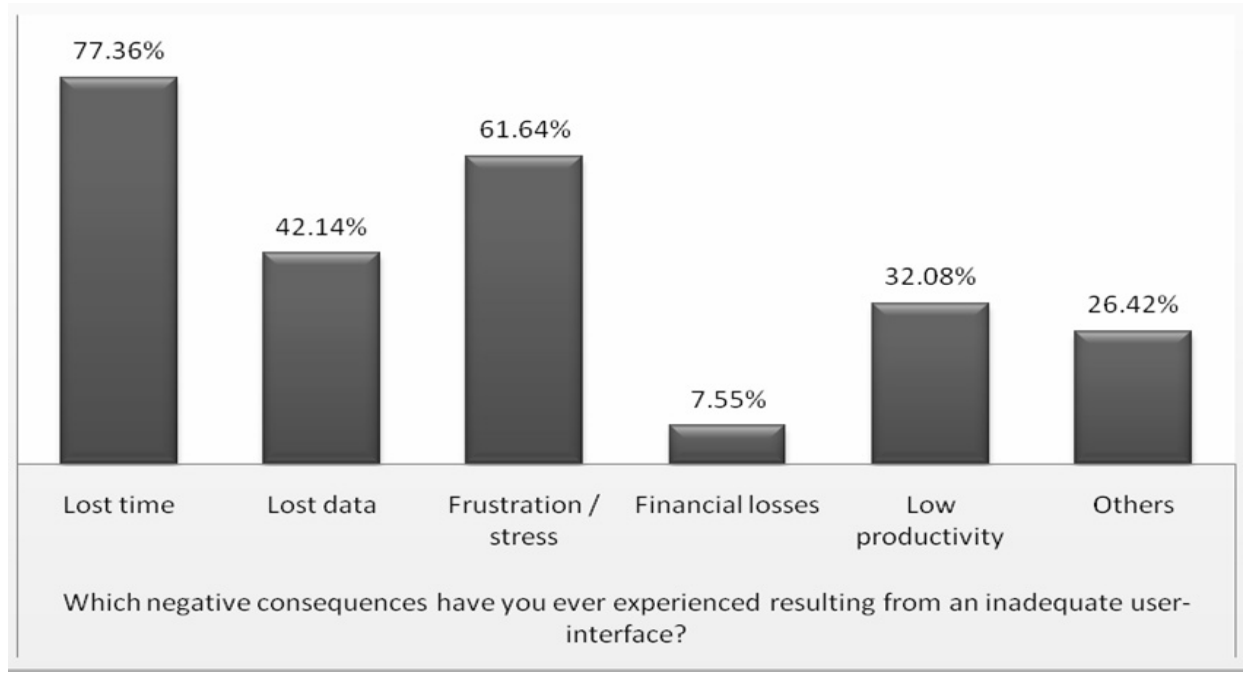

Figure 6. Negative consequences experienced due to an inadequate user-interface 
consequences [20]. From the user point of view, the elimination of any delay, even the occasionally small ones, has the potential to improve work satisfaction and emotional state of mind which may determine an increased productivity and a decreased stress. The delay problems in human-computer interaction have not been solved by the increasing of the computing power.

Therefore, the tailorable software developers should make more efforts in order to provide tailoring features which conduct to an enduser developed system which meet the user expectation for system response time.

\section{Conclusions}

The information systems usage involves a wide range of risks: from intentional to unintentional information systems misuse; from malware to human errors; etc. Most of these risks can be mitigated or even eliminated by providing an adequate level of information system usability. When the information system includes advanced tailoring features, the main risk is to obtain an end-user tailored system which lack of usability.

Staring from the assumption that a user which understands the usability aspects and the interface importance is more likely to tailor a usable system, the results of the study presented in this paper show that the users (the survey participants), as secondary application designers, are aware of the importance of the main usability criteria of the information systems they frequently use and of the necessity of a high level of these usability criteria: effectiveness, efficiency and satisfaction.

The results show the necessity to pay more attention in the information systems design to the user-interface response time, error messages, and to personal data protection.

The low number of the participants does not allow making general conclusions regarding the survey's results but it can provide the basis for a wider and deeper study.

\section{REFERENCES}

1. SHNEIDERMAN, B., A Second Path to HCI Innovation: Generative Theories Tied to User Needs. from Computer Science Department at Tufts University, 2006: (availale at http://www.cs.tufts.edu/ jacob/workshop/papers/shneiderman.pdf, consulted on 12.04.2010).

2. FILIP, F. G., Sisteme Suport pentru Decizii (1st ed.). Bucharest: Technical Publishing House, 2004.

3. SUDUC, A. M., M. BIZOI, L. DUTA, G. GORGHIU, Interface Architecture for a Web-Based Group Decision Support System. Studies in Informatics and Control, 18 (3), Sept., 2009, pp. 241-246.

4. SCHLUNGBAUM, E. Model-based User Interface Software Tools Current State of Declarative Models, Technical Report 96-30, Graphics, Visualization and Usability Center. Georgia Institute of Technology, 1996: (http://smartech.gatech.edu/bitstream/185 3/3516/1/96-30.pdf, consulted on 12.04.2010)

5. BOSCH, J., P. O. BENGTSON, Assessing Optimal Software Architecture Maintability. Fifth European Conference on Software Maintainability and Reengineering, 2001, pp. 168-176.

6. SHNEIDERMAN, B., H. HOCHHEISER, Universal Usability as a Stimulus to Advanced Interface Design. Behaviour and Information Technology , 20 (5), 2001, pp. 367-376.

7. FISCHER, G., K. NAKAKOJI, Y. YE, Metadesign: Guidelines for Supporting Domain Experts in Software Development. IEEE Software , 26 (5), 2009, pp. 37-44.

8. LIEBERMAN, H., F. PATERNO, M. KLANN, V. WULF, End-user Development: An Emerging Paradigm. In H. Lieberman, F. Paterno, \& V. Wulf (Eds.), End-user development, Berlin, Netherlands: Springer, pp. 9-15.

9. MØRCH, A. I., G. STEVENS, M. WON, Component-Based Technologies for 
End-User Development. Comm. of the ACM, 47 (9), 2004, pp. 59-62.

10. GERMONPREZ, M., D. HOVORKA, F. COLLOPY, A Theory of Tailorable Technology Design. Journal of the Association for Information Systems, 8 (6), 2007, pp. 351-367.

11. MCGILL, T., C. KLISC, End-User Perceptions of the Benefits and Risks of End-User Web Development. In G. Kelley, Selected Readings on Information Technology Management: Contemporary Issues, IGI Global 2009, p. 212.

12. MØRCH, A. I., Tailoring Tools for System Development. 10 (2), 1998, pp. 22-30.

13. BEVAN, N., Classifying and Selecting UX and Usability Measures. Proceedings of Meaningful Measures: Valid Useful User Experience Measurement (VUUM), 5th COST294MAUSE Open Workshop, Reykjavik: Institute of Research in Informatics of Toulouse. 2008, pp. 13-18.

14. SUDUC, A.-M., M. BIZOI, F. G. FILIP, Aspecte legate de interfețele omcalculator pentru reducerea riscurilor utilizării sistemelor informatice. Eversion publised in 2010, Romanian Academy, National Institute of Economic Research, 2009 (http://www.ince.ro/ Riscuri_Suduc.pdf, consulted on 12.04.2010).
15. QUESENBERY, W., What Does Usability Mean: Looking Beyond 'Ease of Use'. Retrieved 2009, from WQusability: (http://www.wqusability.com/articles/mo re-than-ease-of-use.html, consulted on 12.04.2010).

16. BEVAN, N., Measuring Usability as Quality of Use. Software Quality Journal, 4, 1995, pp. 115-150.

17. BEVAN, N., Criteria for Selecting Methods in User-centred Design. IUSED'09 Workshop, INTERACT 2009. Uppsala, Sweden, 2009.

18. SHNEIDERMAN, B., C. PLAISANT, Designing the User Interface: Strategies for Effective HumanComputer Interaction (4th ed.). Addison-Wesley, 2005.

19. SUDUC, A.-M., F. G. FILIP, Riscuri ale utilizarii inadecvate a sistemelor informatice. Studii si cercetari economice, 2008, p. 72 (In Romanian).

20. SZAMEITAT, A. J., J. RUMMEL, D. P. SZAMEITAT, Behavioral and Emotional Consequences of Brief Delays in Human-Computer Interaction. International Journal of Human-Computer Studies, 67 (7), 2009, pp. 561-570. 